\title{
Solitary accessory and papillary muscle hypertrophy manifested as dynamic mid-wall obstruction and symptomatic heart failure: diagnostic feasibility by multi-modality imaging
}

Kuo-Tzu Sung ${ }^{1}$, Chun-Ho Yun ${ }^{2,3}$, Charles Jia-Yin Hou ${ }^{1,3}$ and Chung-Lieh Hung 1,3,4*

\begin{abstract}
Background: Solitary papillary muscle (PM) hypertrophy is an unique type of hypertrophic cardiomyopathy (HCM), which is characterized by predominant papillary muscle hypertrophy sparing the rest of other left ventricular segments. It has recently drawn our attention about the mechanism of left ventricular mid-cavity obstruction and the influence of pressure gradient in the left ventricular outflow tract (LVOT), thus carries clinical importance.

Case presentation: We reported a symptomatic, 83-year-old woman who presented with dynamic, high resting left ventricle (LV) mid-wall gradient without obvious septal hypertrophy or systolic anterior motion (SAM). Subsequent real-time (RT) three-dimensional echocardiography (3DE) and cardiac magnetic resonance imaging (MRI) demonstrated large, hypertrophic accessory papillary muscles squeezing mid-cavity of left ventricle producing dynamic pressure gradient during systole in the absence of left ventricular wall anomalies.

Conclusion: We proposed that combined use of echocardiography particularly RT-3DE and cardiac magnetic resonance imaging (MRI) can accurately identify this specific type of hypertrophic cardiomyopathy without remarkable traditional features.
\end{abstract}

Keywords: Solitary papillary muscle hypertrophy, LVOT obstruction, Hypertrophic cardiomyopathy

\section{Background}

Hypertrophic obstructive cardiomyopathy (HOCM) refers to those subjects with significant dynamic left ventricular outflow tract (LVOT) obstruction due to mechanical causes, with most presents with asymmetrical septal hypertrophy resulting in dynamic systolic anterior motion (SAM) of mitral leaflets [1].

Solitary papillary muscle (PM) hypertrophy, a peculiar form of HCM manifested as predominant PM hypertrophy sparing the rest of other LV segments, has recently gained much attention owing to its mechanical consequences on left ventricular outflow tract (LVOT) pressure gradient formation $[2,3]$.

\footnotetext{
* Correspondence: jotaro3791@gmail.com

'Division of Cardiology, Department of Internal Medicine, Mackay Memorial Hospital, Taipei, Taiwan

${ }^{3}$ Department of Medicine, Mackay Medical College, and Mackay Medicine, Nursing and Management College, Taipei, Taiwan

Full list of author information is available at the end of the article
}

\section{Case presentation}

A 83-year-old woman with history of hypertension and hyperlipidemia. The blood pressure and hyperlipidemia were well-controlled with medication. She was admitted to our hospital with chest pain on effort and exertional shortness of breath. Her vital sign was stable with blood pressure 131/70 $\mathrm{mmHg}$ and heart rate 67 beats per minute at initial presentation. A mid-systolic ejection murmur was heard along the left sternal border with chest X-ray showed minor pulmonary congestion. Incidental high resting LV mid-wall pressure gradient ( $86 \mathrm{mmHg}$, Figure $1 \mathrm{~A})$ was shown by 2dimensional echocardiography without LV septal wall thickness $(8.5 \mathrm{~mm})$. The $\mathrm{LV}$ end-diastolic volume was $90 \mathrm{ml}$, and LV end-systolic volume was $27 \mathrm{ml}$. Apparently hypertrophied anterolateral (A) and posteromedial (P) papillary muscles together with a large, third accessory PM were observed (Figure 1C). Neither aortic stenosis nor SAM was observed. Complete ECG disclosed obvious U wave 

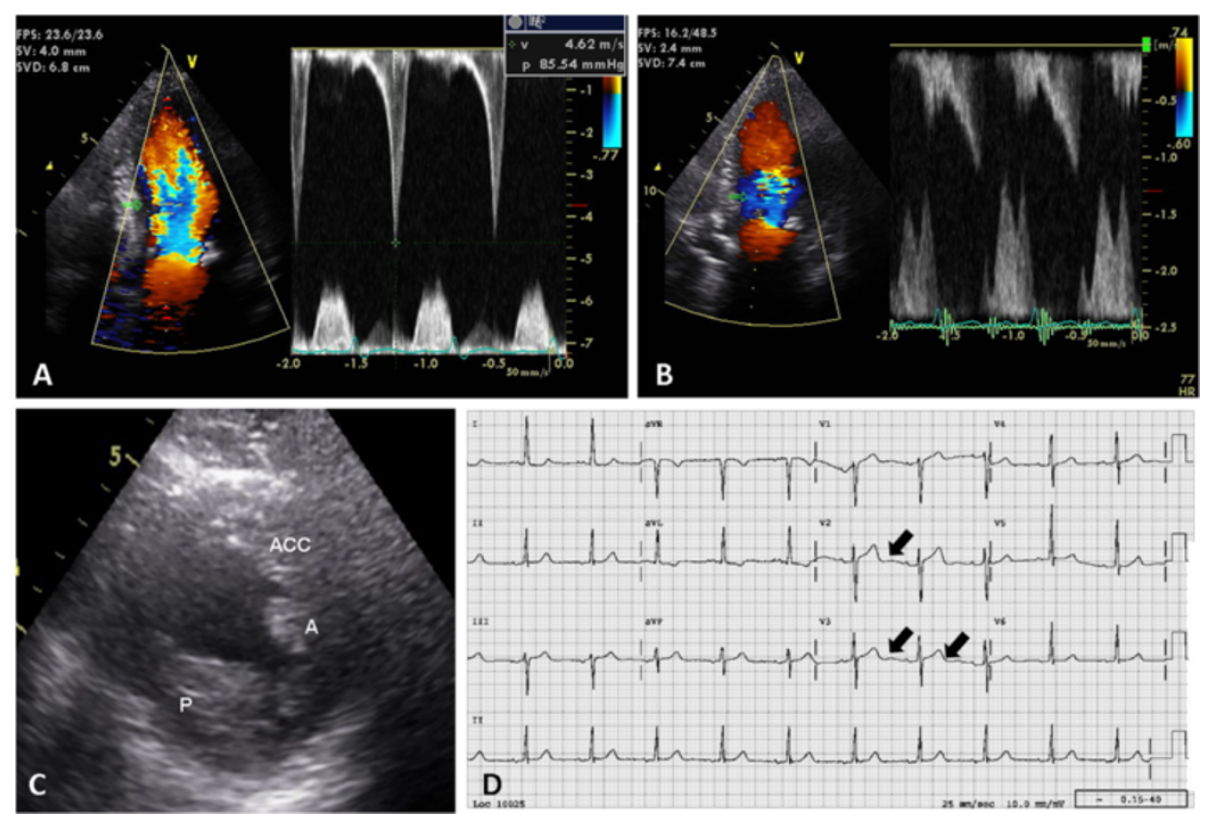

Figure 1 2D Echocardiography and complete ECG. (A) Continuous wave Doppler tracing of the LV mid-wall showed the peak pressure gradient was $85.5 \mathrm{mmHg}$ at rest. (B) Subsequent continuous wave Doppler tracing eight hours later showed normal pressure gradient (estimated to be $5 \mathrm{mmHg}$ ). (C) In short axis view, apparently hypertrophied anterolateral and posteromedial papillary muscles together with a large, third accessory PM were observed (A: anterolateral papillary muscle, P: posteromedial papillary muscle, ACC: accessory papillary muscle). (D) Complete ECG showed prominent $\mathrm{U}$ wave in $\mathrm{V} 1-\mathrm{V} 4$.

(V1-V4) with normal QT interval (416ms, Figure 1D). Blood level of B-natriuretic peptide was obviously elevated $(227 \mathrm{pg} / \mathrm{ml})$.

Repeated 2D transthoracic echocardiogram during hospitalization revealed no more pressure gradient (plummeted to $5 \mathrm{mmHg}$ ) after holding diuretics (Figure 1B). Meanwhile, she was in euvolemic state with blood pressure $128 / 76 \mathrm{mmHg}$ and heart rate 62 beats per minute. To further clarify the spatial relationships between these hypertrophied PMs and other LV wall segments, real-time 3D echocardiography (RT-3DE) was performed and showed nearly complete LV mid-wall cavity obliteration by the these morphological abnormal PMs during end-systolic phase (Figure 2A-B; Additional files 1, 2 and 3). Subsequent MRI study demonstrated normal LV volume (end-diastolic volume: $71.9 \mathrm{ml}$ ), unremarkable $\mathrm{LV}$ wall abnormalities, normal global LV mass index $\left(79.9 \mathrm{gm} / \mathrm{m}^{2}\right)$ though significantly hypertrophied PMs (total PM mass: 20.2 gm; $13.4 \mathrm{gm} / \mathrm{m}^{2}$ indexed to body surface area; Figure $2 \mathrm{C}-\mathrm{D}$ ) without visible perfusion defects or delayed hyperenhancement (DHE). High temporal resolution Tissue Doppler Imaging ( $>250$ frames per second) further demonstrated markedly diminished diastolic mitral annulus relaxation velocities $(1.8 \mathrm{~cm} / \mathrm{sec}$ for basoseptal and $4.3 \mathrm{~cm} / \mathrm{sec}$ for basolateral segments; Figure 2E-F). When PMs mass were taken into account (up to $16.8 \%$ LV mass; Figure 3A-B), the total LV mass may reach the echocardiographic criteria for LV hypertrophy [4] (defined as LV mass index $>95 \mathrm{gm} / \mathrm{m}^{2}$ in women and $>115 \mathrm{~g} / \mathrm{m}^{2}$ in men). Beta-blockade was then prescribed and the symptoms improved drastically during the subsequent follow up.

\section{Conclusions}

So far, left ventricular hypertrophy remained the predominant and major phenotypic component of hypertrophied cardiomyopathy [1]. Few cases of dynamic LVOT or midcavity obstruction in relation to various morphological papillary muscle anomalies had been reported before, and these may include bifid [5] or octopus papillary muscle [6], accessory [7], single [2], or solitary papillary muscle hypertrophy [8]. Papillary muscle hypertrophy, when defined by at least one of the two papillary muscles is more than $1.1 \mathrm{~cm}$ in either vertical or horizontal diameter, had been recently shown to be a phenotypic variant of HCM $[8,9]$. Not until recently, morphological papillary muscle anomalies without features of phenotypic LV hypertrophy (isolated papillary muscle hypertrophy) had gradually been recognized to be an uncommon HCM variant $[8,10]$. The clinical features of LV mid-cavity obstruction caused by papillary muscle hypertrophy may vary greatly from asymptomatic to dyspnea, angina, syncope, and even sudden cardiac death [8-10], with prominent $U$ wave and left ventricular hypertrophy by ECG $[11,12]$, which is concordant with our current case findings.

While HCM subjects with concomitant morphological papillary muscle anomalies may present with 

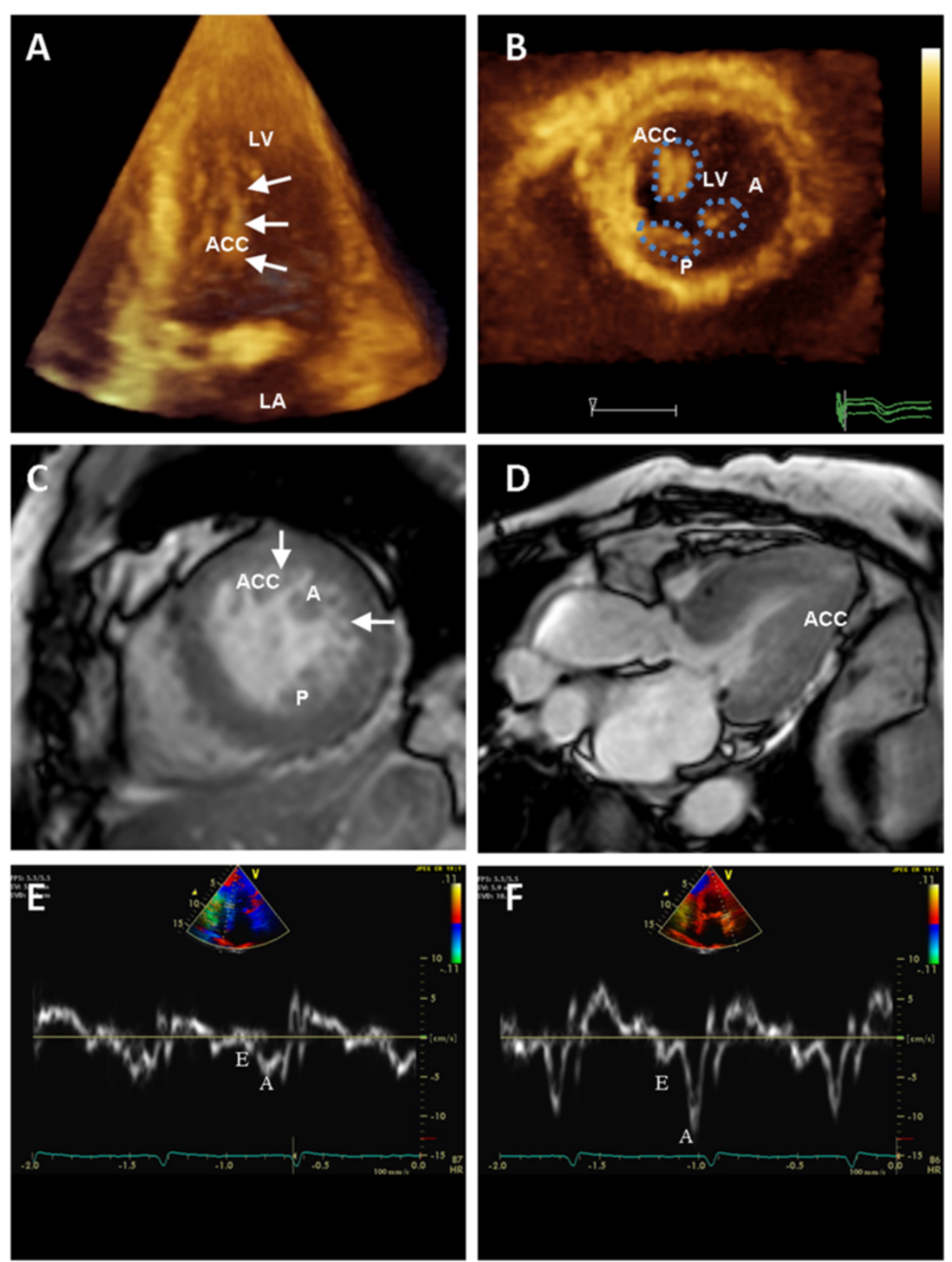

Figure 2 Real 3D echocardiography, MRI, and tissue doppler imaging. (A) 2D echocardiogram in the short-axis section of the left ventricle demonstrated uncommonly enlarged papillary muscles (A: anterolateral papillary muscle, P: posteromedial papillary muscle, ACC: accessory papillary muscle). (B) Real time 3D Echocardiography demonstrated that LV mid-cavity was almost obliterated during end-systolic phase from five chamber view (Additional file 1, movie 1). A: anterolateral papillary muscle, LA: left atrium, LV: left ventricle. (C) Contrast-enhanced MRI from LV short-axis showed two large papillary muscles as well as adjacent abundant muscular trabeculae producing mid-cavity obstruction during systolic phase. (D) MRI from long-views showed anterolateral papillary muscle squeezing left ventricular outflow tract against LV septum during systolic phase. High temporal resolution Tissue Doppler Imaging showed markedly diminished diastolic mitral annulus relaxation velocities, $1.8 \mathrm{~cm} / \mathrm{sec}$ for basoseptal (E) and $4.3 \mathrm{~cm} / \mathrm{sec}$ for basolateral segments (F).

higher degree of resting LVOT gradient [13], it is not surprising that subjects with increasing number of hypertrophied papillary muscles with unchanged ventricular cavity size may have higher probability of causing LV chamber obliteration during systole. So far, there are reports presented with isolated papillary muscle hypertrophy and normal LV wall thickness. Herein, we report a case of morphological papillary muscle anomalies featured by dynamic LV mid-wall obstruction, with subjective exertional chest pain and dyspnea. We further observed in our case that severely impaired LV diastolic function and clinical 

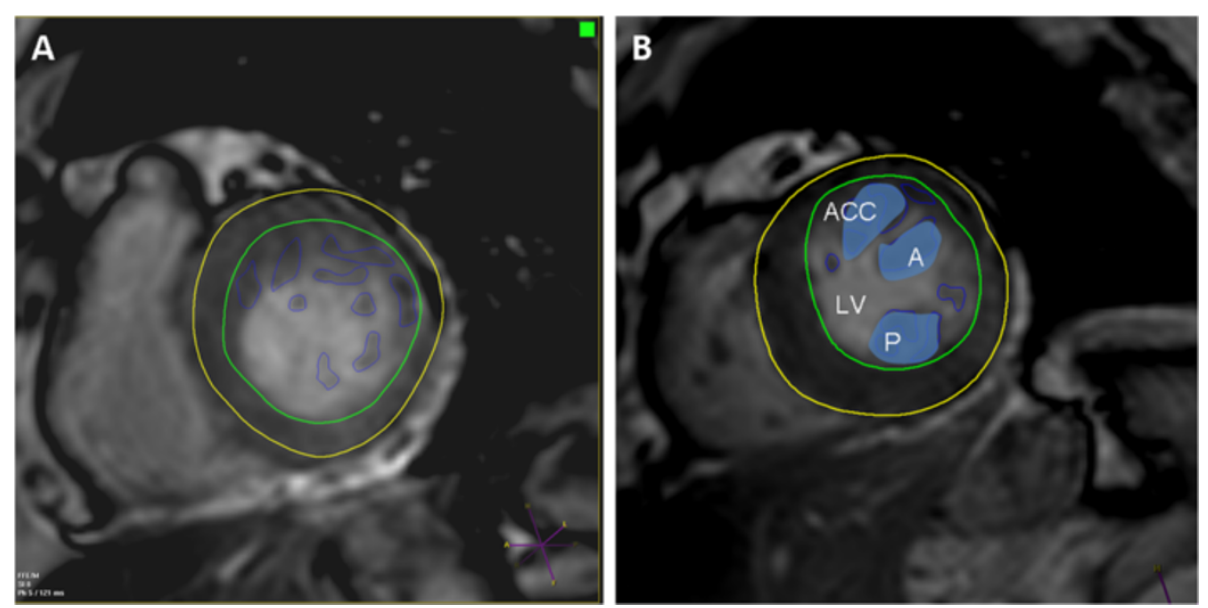

Figure 3 Cardiac MRI, short axis view. (A) Unremarkable LV wall abnormality with normal LV mass at end-diastolic phase by MRI; (B) Hypertrophy PMs as well as existence of accessory PM (ACC) shown.

heart failure [14] may occur as a consequence of excessive, redundant papillary muscle mass with normal LV mass [7].

Current guidelines for LV mass calculation do not take papillary muscle mass into account, while our relevant findings may suggest include papillary muscles in LV mass assessment, especially for these morphologically abnormal papillary muscle subjects.

Solitary papillary muscle hypertrophy as an uncommon variant form of HCM with coexisted additional, accessory papillary muscle may develop abnormally high resting LV mid-wall pressure gradient without SAM or significant regional LV wall hypertrophy. Cardiac MRI and RT-3DE may have their peculiar roles in uncovering these cardiac morphological/structural anomalies aiming for a more comprehensive analysis on their spatial relationships.

In conclusion, we recommended that for subjects with unusually high LV mid-wall or LVOT pressure gradient with unrevealing regional LV segment anomalies, RT3DE and MRI should be considered as a screening tool to disclose these under-diagnosed, specific HCM subjects in daily routine.

\section{Consent}

Written informed consent was obtained from the patient for publication of this Case report and any accompanying images. A copy of the written consent is available for review by the Editor-in-Chief of this journal.

\section{Additional files}

Additional file 1: Real time 3D Echocardiography, four chamber view.
Additional file 2: Real time 3D Echocardiography, short axis view. Additional file 3: Real time 3D echocardiography sequences in short axis view, divided the left ventricle into 9 slices during end-diastolic phase.

\section{Abbreviations}

LV: Left ventricle; RT: Real time; 3DE: three-dimensional echocardiography; MRI: magnetic resonance imaging; PM: Papillary muscle; HCM: Hypertrophic cardiomyopathy; HOCM: Hypertrophic obstructive cardiomyopathy; LVOT: Left ventricular outflow tract; SAM: Systolic anterior motion; DHE: Delayed hyperenhancement.

\section{Competing interests}

The authors declare that they have no competing interests.

\section{Authors' contributions}

KTS was the primary author of the text. CHY assisted in image acquisition and retouching. CLH conceived of the report, provided the images, and modified the manuscript. JYH provided additional supervision. All authors have read and approved the final manuscript.

\section{Author details}

'Division of Cardiology, Department of Internal Medicine, Mackay Memorial Hospital, Taipei, Taiwan. ${ }^{2}$ Department of Radiology, Mackay Memorial Hospital, Taipei, Taiwan. ${ }^{3}$ Department of Medicine, Mackay Medical College, and Mackay Medicine, Nursing and Management College, Taipei, Taiwan.

${ }^{4}$ Cardiovascular Medicine, Mackay Memorial Hospital, No. 92, Section 2,

Chung Shan North Road, Taipei, Taiwan.

Received: 3 October 2013 Accepted: 11 February 2014

Published: 10 March 2014

\section{References}

1. Williams LK, Frenneaux MP, Steeds RP: Echocardiography in hypertrophic cardiomyopathy diagnosis, prognosis, and role in management. Eur J Echocardiogr 2009, 10:iiig-iiii4.

2. Austin BA, Kwon DH, Smedira NG, Thamilarasan M, Lever HM, Desai MY: Abnormally thickened papillary muscle resulting in dynamic left ventricular outflow tract obstruction: an unusual presentation of hypertrophic cardiomyopathy. J Am Soc Echocardiogr 2009, 22(105):105-106.

3. Pacileo M, Cirillo P, Prastaro M, Chiariello M: Latent left ventricular outflow tract obstruction induced by abnormal hypertrophic papillary muscle caused myocardial ischemia. Int J Cardiol 2009, 132:270-272. 
4. Barbieri A, Bursi F, Mantovani F, Valenti C, Quaglia M, Berti E, Marino M, Modena MG: Left ventricular hypertrophy reclassification and death: application of the Recommendation of the American Society of Echocardiography/European Association of Echocardiography. Eur Heart J Cardiovasc Imaging 2012, 13:109-117.

5. Ker J: Bigeminy and the bifid papillary muscle. Cardiovasc Ultrasound 2010, 8:13.

6. Shah AS, Kukar A, Chaudhry FA, Sherrid MV: Unusual anomalous single papillary muscle causing symptomatic mid left ventricular cavity obstruction: octopus papillary muscle. J Am Soc Echocardiogr 2006, 19:939.

7. Harrigan CJ, Appelbaum E, Maron BJ, Buros JL, Gibson CM, Lesser JR, Udelson JE, Manning WJ, Maron MS: Significance of papillary muscle abnormalities identified by cardiovascular magnetic resonance in hypertrophic cardiomyopathy. Am J Cardiol 2008, 101:668-673.

8. Kobashi A, Suwa M, Ito T, Otake Y, Hirota Y, Kawamura K: Solitary papillary muscle hypertrophy as a possible form of hypertrophic cardiomyopathy. Jpn Circ J 1998, 62:811-816.

9. Maron MS: Clinical utility of cardiovascular magnetic resonance in hypertrophic cardiomyopathy. J Cardiovasc Magn Reson 2012, 14:13.

10. Correia AS, Pinho T, Madureira AJ, Araujo V, Maciel MJ: Isolated papillary muscle hypertrophy: a variant of hypertrophic cardiomyopathy? Do not miss a hypertrophic cardiomyopathy. Eur Heart J Cardiovas Imaging 2013, 14:296.

11. Ker J: Solitary papillary muscle hypertrophy: a new echo-electrocardiographic syndrome? A case report. Angiology 2007, 58:502-503.

12. Patil NP, Katti K: Unusual papillary muscle hypertrophy in a septuagenarian. J Oscul Surg 2011, 142:704-705.

13. Kwon DH, Setser RM, Thamilarasan M, Popovic ZV, Smedira NG, Schoenhagen P, Garcia MJ, Lever HM, Desai MY: Abnormal papillary muscle morphology is independently associated with increased left ventricular outflow tract obstruction in hypertrophic cardiomyopathy. Heart 2008, 94:1295-1301.

14. Kindermann M: How to diagnose diastolic heart failure: a consensus statement on the diagnosis of heart failure with normal left ventricular ejection fraction by the Heart Failure and Echocardiography Associations of the European Society of Cardiology. Eur Heart J 2007, 28:2686. author reply 2686-2687.

doi:10.1186/1471-2261-14-34

Cite this article as: Sung et al:: Solitary accessory and papillary muscle hypertrophy manifested as dynamic mid-wall obstruction and symptomatic heart failure: diagnostic feasibility by multi-modality imaging. BMC Cardiovascular Disorders 2014 14:34.

\section{Submit your next manuscript to BioMed Central and take full advantage of:}

- Convenient online submission

- Thorough peer review

- No space constraints or color figure charges

- Immediate publication on acceptance

- Inclusion in PubMed, CAS, Scopus and Google Scholar

- Research which is freely available for redistribution
C Biomed Central 